\title{
Prediction of Torsional Strength for Very High Early Strength Geopolymer
}

\author{
Woraphot PRACHASAREE ${ }^{1 *}$, Abideng HAWA ${ }^{2}$ \\ ${ }^{1}$ Department of Civil Engineering, Prince of Songkla University, Hat Yai, Songkhla, Thailand 90112 \\ ${ }^{2}$ Department of Civil Engineering, Princess of Naradhiwas University, Amphur Muang, Narathiwat, Thailand, 96000 \\ cross ref http://dx.doi.org/10.5755/j01.ms.23.4.17280
}

Received 16 December 2016; accepted 05 March 2017

\begin{abstract}
Very early high strength geopolymers are gaining acceptance as alternative repair materials for highways and other infrastructure. In this study, a very rapid geopolymer binder based on Metakaolin (MK) and Parawood ash (PWA), developed by the authors, was experimentally tested and a prediction model for its torsional strength is proposed. The geopolymer samples were subjected to uniaxial compression, flexural beam, and torsion tests. The modulus of rupture and torsional strength in terms of compression strength were found to be well approximated by $0.7\left(f^{\prime} c\right)^{1 / 2}$ and $1 / 7\left(x^{2} y\right)$ $\left(f^{\prime}\right)^{1 / 2}$, respectively. Also an interaction relation to describe combined bending and torsion was developed in this study. In addition, the effects of aspect ratio $(\mathrm{y} / \mathrm{x})$ were studied on both torsional strength and combined bending and torsion. It was found that an aspect ratio of $y / x=3$ significantly reduced the torsional resistance, to about $50 \%$ of the torsional strength of a square section.

Keywords: torsion, strength, geopolymer, modulus of rupture, concrete.
\end{abstract}

\section{INTRODUCTION}

In geopolymer synthesis, raw materials such as fly ash (FA), metakaolin (MK), and volcanic ash (VA) are mixed with concentrated alkaline solution under hydrothermal conditions. Normally these raw materials include alkaliactivated alumino-silicate mineral binder. A 3-D network of $\mathrm{Si}-\mathrm{O}-\mathrm{Al}-\mathrm{O}$ bonds is formed by polymerization in the alkaline environment [1-4]. Geopolymer binders can have excellent physical and chemical properties for a wide range of civil engineering and infrastructure applications, particularly in structural and non-structural repairs. Typically, concrete or cement based materials for structural repairs must provide high early compressive strength with rapid strength development and short curing time. Very rapid setting repair materials, such as very early high strength geopolymer binder, require a shorter period for setting and give high strength instantaneously at completion of the repair job. In highway and infrastructure repairs, there are economic costs associated with traffic closing or obstruction that need to be minimized, and potential new repair materials may provide effective solutions. Therefore, the geopolymers are gaining acceptance as alternative materials with economic advantages. Very high early strength geopolymer binders have widely studied and developed by many researchers [5-10]. Rapid setting time of the developed binders was particuarly emphasized in these studies. To develop fast setting repair materials, modified cement with magnesia phosphate were experimetally evaluated $[5,6]$. Properties and applications of cement mortar with magnesiaphosphate were studied by Yang et al. [7]. Comprehensive research on repair materials for concrete pavements is also available [6, 7, 9]. Modified Portland cement has been investigated at various mix proportions of PCC and latex

\footnotetext{
${ }^{*}$ Corresponding author. Tel.: +66-074-287-114; fax: +66-074-459-396.
} E-mail address: mr.woraphot@gmail.com (W. Prachasaree)
[8,9]. Recently, high early strength geopolymers from metakaolin (MK) and Parawood ash (PWA) have been developed and evaluated for their mechanical properties by the current authors [10,11]. In Southeast Asia, Parawood is mostly used as raw material for biomass power plants. Parawood ash (PWA) is one of residual products during the combination process of Parawood lumber and waste for electricity generation. Previous studies on the use of PWA as a material in geopolymer have still been rarely available $[10,11]$. The feasibility study on Metakaolin based geopolymer containing PWA and Oil palm ash was investigated to develop high early compressive strength binder [11]. The geopolymer samples were tested for compressive strength and drying shrinkage, and for bond strength to Portland cement mortar with slant shear test. It was found that PWA significantly reduces drying shrinkage of test specimens [11]. Based on previous studies, knowledge concerning the mechanical properties and behaviors of geopolymer containing PWA are necessarily accomplished before field applications. Other properties such as modulus of rupture and torsional strength are still not well established even for normal strength geopolymer, and in particular not the high early strength variants. Experimental data on these properties are rare, so further research on modulus of rupture and torsional strength was necessary. Relations between the other evaluated mechanical properties and the compressive strength are assessed in the current study. In addition, the interaction of bending and torsion is subjected to a parametric study. This study will fill some gaps in the current knowledge about alternative repair materials, particularly for field applications.

\section{MATERIALS}

In this study, very high early strength geopolymer samples were prepared from the raw materials Metakaolin (MK), Parawood ash (PWA), river sand, sodium silicate, 
sodium hydroxide, and water. The Metakaolin was calcined at approximately $750{ }^{\circ} \mathrm{C}$ for 2 hours and ground in a ball mill to obtain MK particles with average size $\left(\mathrm{d}_{50}\right)$ of $6.31 \mu \mathrm{m}$. The PWA is a residual combination product from Para rubber wood, and was collected from biomass thermal power plants in southern Thailand. The PWA was ground in a ball mill for 4 hours. The particle size distributions of MK and PWA were evaluated by laser scattering and are shown in Fig. 1. To analyze the chemical composition of MK and PWA, X-ray fluorescence (XRF) spectrometry was used (Fig. 2). In general, the morphology of a geopolymer is mostly determined by the raw materials. The particle morphologies of MK and PWA were examined using scanning electron microscopy (SEM). It was found that both MK and PWA particles are mainly irregular in shape and of varying sizes.

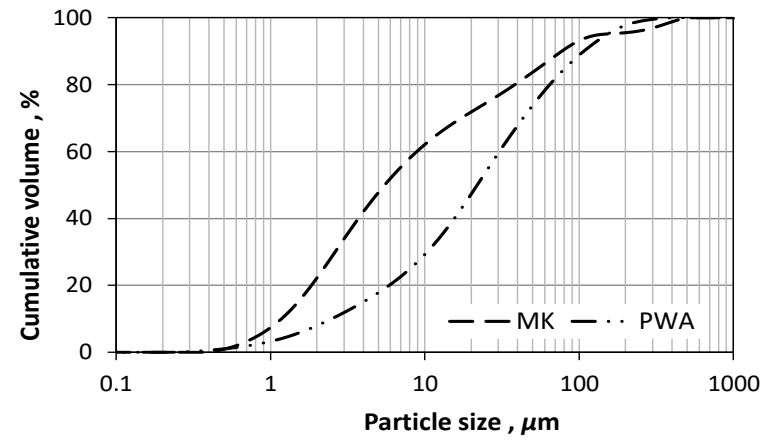

Fig. 1. Particle size distributions of the main mixture components

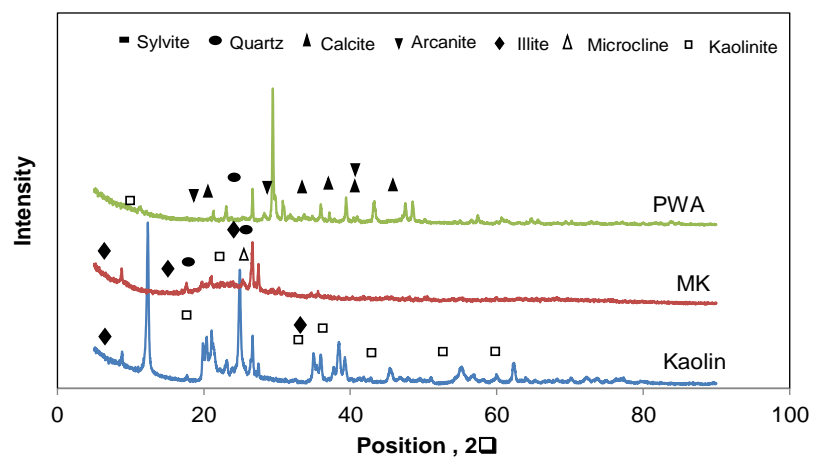

Fig. 2. XRD patterns of PWA, MK and natural kaolin

However, the PWA particles were the larger and rounder of the two, as shown in Fig. 3. In addition, the loss on ignition, specific surface area, and chemical composition are summarized in Table 1 for both MK and PWA. The main components in $\mathrm{MK}$ were 50 percent $\mathrm{SiO}_{2}$ and 41 percent $\mathrm{Al}_{2} \mathrm{O}_{3}$, confirming that it can be used in Si$\mathrm{Al}$ cementitious materials.

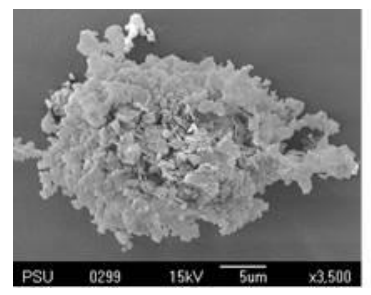

a

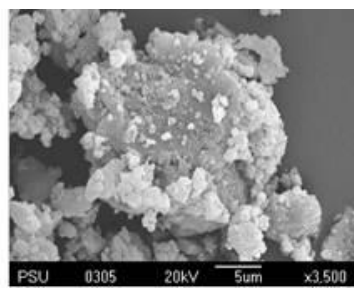

b
Fig. 3. SEM micrographs of the main raw materials: $\mathrm{a}$ - metakaolin (MK); b-parawood ash (PWA)
To ensure high alkaline activity in the geopolymer mix, the ratio of calcium oxide and magnesium oxide to silicon dioxide $\left(\mathrm{SiO}_{2}\right)$ should exceed one (EN 197-1, [12]). The main chemical components of PWA were 16 percent $\mathrm{K}_{2} \mathrm{O}$ and 41 percent $\mathrm{CaO}$ (Table 1). It was found that the PWA used in this study had high alkalinity. The actual alkaline activator was prepared from sodium hydroxide ( $\mathrm{NaOH}, 98 \%$ pure flakes) with sodium silicate solution (14.1\% $\mathrm{Na}_{2} \mathrm{O}, 27.7 \% \mathrm{SiO}_{2}$, and $56.3 \% \mathrm{H}_{2} \mathrm{O}$ by weight) and water. The local river sand used as the fine aggregate had $4.75 \mathrm{~mm}$ maximum size and specific gravity 2.51 . The $1.48 \%$ water absorption of the fine aggregate was determined according to ASTM C 128 [13]. To obtain test samples with compressive strengths from $40 \mathrm{MPa}$ to $70 \mathrm{MPa}$, four mixture recipes were designed and prepared varying the amounts of MK and PWA. The proportions of MK and PWA were designed based on the previous study by the authors [10].

Table 1. Chemical compositions and physical properties of the main raw materials

\begin{tabular}{|l|c|c|}
\hline \multicolumn{1}{|c|}{ Oxide } & PWA & MK \\
\hline $\mathrm{SiO}_{2}$ & 2.57 & 50.30 \\
\hline $\mathrm{Al}_{2} \mathrm{O}_{3}$ & 0.53 & 41.02 \\
\hline $\mathrm{Fe}_{2} \mathrm{O}_{3}$ & 0.56 & 1.05 \\
\hline $\mathrm{CaO}$ & 41.19 & 0.33 \\
\hline $\mathrm{TiO}_{2}$ & - & 1.50 \\
\hline $\mathrm{MgO}$ & 4.52 & - \\
\hline $\mathrm{K} 2 \mathrm{O}$ & 16.11 & 4.08 \\
\hline Other & 10.78 & - \\
\hline $\begin{array}{l}\text { Loss on ignition } \\
(\text { LOI) }\end{array}$ & 23.74 & 1.72 \\
\hline $\begin{array}{l}\text { Specific surface area } \\
\left(\mathrm{m}^{2} / \mathrm{g}\right) \text { BET }\end{array}$ & 8.71 & 13.61 \\
\hline $\mathrm{d}_{10}, \mu \mathrm{m}$ & 2.860 & 1.352 \\
\hline $\mathrm{d}_{50}, \mu \mathrm{m}$ & 25.128 & 6.308 \\
\hline $\mathrm{d}_{90}, \mu \mathrm{m}$ & 123.450 & 88.803 \\
\hline
\end{tabular}

Table 2. Mixture proportions and molar ratios in the mixture formulations

\begin{tabular}{|c|c|c|c|c|c|c|}
\hline \multirow{2}{*}{ Mixture* } & \multicolumn{2}{|c|}{$\begin{array}{c}\text { Proportion, } \\
\%\end{array}$} & \multicolumn{4}{c|}{ Molar ratio } \\
\cline { 2 - 7 } & $\mathrm{MK}$ & PWA & $\begin{array}{c}\mathrm{SiO}_{2} / \\
\mathrm{Al}_{2} \mathrm{O}_{3}\end{array}$ & $\begin{array}{c}\mathrm{CaO} / \\
\mathrm{SiO}_{2}\end{array}$ & $\mathrm{Na}_{2} \mathrm{O} / \mathrm{SiO}_{2}$ & $\begin{array}{c}\mathrm{H}_{2} \mathrm{O} / \\
\mathrm{Na}_{2} \mathrm{O}\end{array}$ \\
\hline $\mathrm{P} 0$ & 100 & 0 & 2.77 & 0.01 & 0.21 & 11.43 \\
\hline $\mathrm{P} 10$ & 90 & 10 & 2.85 & 0.08 & 0.23 & 11.43 \\
\hline $\mathrm{P} 20$ & 80 & 20 & 2.95 & 0.16 & 0.25 & 11.43 \\
\hline $\mathrm{P} 30$ & 70 & 30 & 3.09 & 0.26 & 0.27 & 11.43 \\
\hline
\end{tabular}

*(compressive strengths varied from $40 \mathrm{MPa}$ to $70 \mathrm{MPa}$ )

Note: All mixtures $\mathrm{SS} / \mathrm{N}=2.5, \mathrm{~A} / \mathrm{R}=0.83, \mathrm{~W} / \mathrm{R}=0.45, \mathrm{~S} / \mathrm{R}=3$; where $\mathrm{SS}=$ sodium silicate, $\mathrm{N}=$ sodium hydroxide, $\mathrm{A}=$ sodium silicate + sodium hydroxide, $\mathrm{W}=$ water, $\mathrm{S}=$ sand, $\mathrm{R}=$ the raw materials as $\mathrm{MK}$ and PWA. High $\mathrm{CaO}$ content of raw materials causes large porosity [14]. Then, the increase porosity can lead to degradation of compressive strength However, replacement of raw materials with PWA can reduce shrinkage rate of specimens (for specimens with heat curing at least $2 \mathrm{~h}$ ) $[11,15]$.

Details of the ingredient proportions and molar ratios are shown in Table 2. Each batch was mixed to cast three test specimens each for compression, flexural, and torsion test, per formulation. The ingredients were weighted and mixed manually. The mixing procedure was as follows. 
The alkaline activator (sodium silicate and sodium hydroxide) on mixing reached $74 \pm 2{ }^{\circ} \mathrm{C}$ from reaction heat. Then the PWA and the fine aggregate were blended in with the alkaline activator, to form a fast setting product. For compressive testing, the fresh mixture was poured into an acrylic mold $(50 \times 50 \times 50 \mathrm{~mm})$ following the requirements of ASTM C109 [16]. The flexural and torsional tested samples were cast in a square prism $(25 \times 25 \mathrm{~mm})$ with $285 \mathrm{~mm}$ length. The filled molds were sealed with polyvinyl sheets and cured at $80^{\circ} \mathrm{C}$ temperature for 4 hours. After curing the polyvinyl sheets were removed, then the samples were remolded and left at ambient temperature $\left(30 \pm 2{ }^{\circ} \mathrm{C}\right)$ and relative humidity $(70 \pm 5 \%)$ for 28 days before testing.

\section{METHODOLOGY AND TESTING}

The modulus of rupture, the torsional strength and the axial compression strength were determined by the flexural beam test under a concentrated load at the mid-span and the torsion test. For each sample batch, geopolymer mortar was cast into both cube and prism samples as mentioned in Section 2. The two main sets of experiments were: 1) compressive and flexural beam tests (samples for the same batch), and 2) compressive and torsional tests. The compressive strength of the cube samples was evaluated under uniaxial compression load, while the prism samples were subjected to flexural beam and torsion tests. The details of flexural beam and torsion tests are given as follows: To evaluate the modulus of rupture, prism samples $(25 \times 25 \times 285 \mathrm{~mm})$ were subjected to center point loading at the mid-span (ASTM C293 [17]) with a support span of $200 \mathrm{~mm}$. The prism samples were subjected to a slowly applied load at the center of test span until failure. Schematic of the test set-up is shown in Fig. 4.

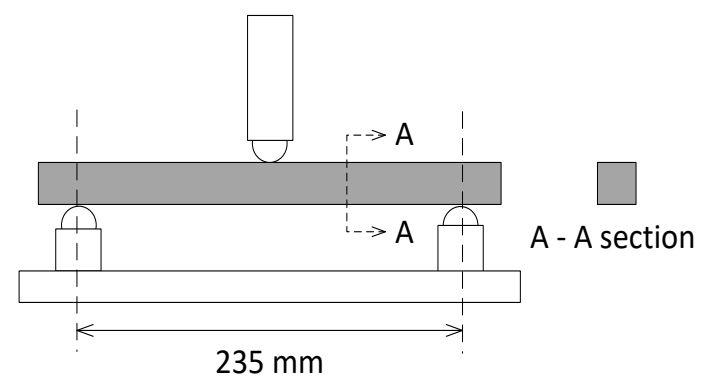

Fig. 4. Schematic set-up for testing prism samples

Modulus of rupture is defined as the failure stress under flexure. Typically, this failure stress is equal to or slightly lower than the failure stress in direct tension. In this study, the failure strength was obtained from the maximum applied sustained load before rupture. For a rectangular cross section, the modulus of rupture can be determined as:

$f_{r}=\frac{3 P L}{2 b h^{2}}$,

where, $P$ is the maximum applied load, $L$ is the test span, and $b$ and $h$ are width and thickness of the sample, respectively.
The prism samples were twisted until failure to evaluate the torsional strength of test samples. In this study, the test procedure concerned only Saint Venant's torsion induced by twisting a cross-section. The testing machine for torsion conducted the torque-twist tests as shown in Fig. 5.

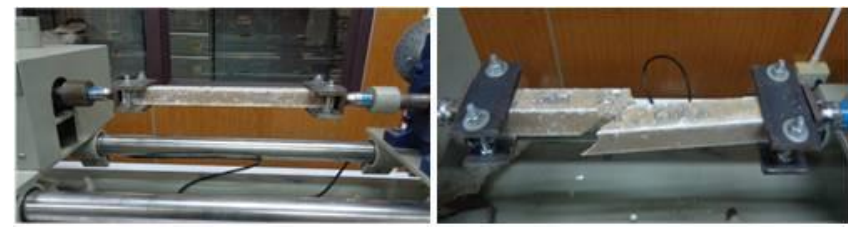

Fig. 5. Torsion test of a prism sample

The prism samples were placed in the steel grips of rotating arms with $200 \mathrm{~mm}$ test span. The steel clips were clamped by applying torque to each bolt to prevent free body rotation within the steel grips. It should be noted that the cross sections at the prism ends were not constrained in the longitudinal direction, so free warping or horizontal moment was still allowed. Torque was applied into the test prism by anchoring one end and rotating the other end. The applied torque and torque reaction are of equal magnitudes but in opposite directions. An axial torsional load cell was attached to the anchored end to measure the reaction torque. The maximum applied torque was recorded and taken as the torsional strength of the test sample.

\subsection{Torsional strength}

When a bar is subjected to torsion, shear stresses are induced in the bar cross sections by the torsional moment. In a solid rectangular section the shear stress varies from the maximum at the centers of long edges to zero at the center of twisting. Under pure torsion, if the principal tension exceeds the tensile strength a diagonal crack will develop and eventually leads to failure. The torsional behavior of a bar before cracking can be predicted with the theory of elasticity. Based on St.Venant's elastic theory, the twist angle per unit length is directly proportional to the applied torque as in Eq. 2, and the maximum shear stress $\left(\tau_{\max }\right)$ is given in Eq. 3 .

$\theta=\frac{T}{K G \alpha x^{3} y}$

$\tau_{\max }=\frac{T}{\alpha x^{2} y}$,

where $K$ is a correction factor accounting for the stiffness loss, $G$ is shear modulus, $\alpha$ is St.Venant's coefficient depending on the ratio $(y / x)$, and $x$ and $y$ are the short and long edge lengths of the rectangular section, respectively.

The torsional strength or cracking strength of a bar under pure torsion can be determined when the principal tensile stress reaches the tensile strength $\left(f^{\prime}{ }_{t}\right)$.

$T=\alpha x^{2} y f_{t}^{\prime}$.

Based on plastic deformation theory, the torsional strength of a bar is still obtained when the principal tensile stress equals the tensile strength $\left(f_{t}^{\prime}\right)$ as well as the torsional strength from elastic theory as in Eq. 4. However, 
St.Venant's coefficient is now replaced by the plastic coefficient $\left(\alpha_{p}\right)$. The torsional strength based on plastic deformation theory is given in Eq. 5 .

$T_{p}=\alpha_{p} x^{2} y f_{t}^{\prime}$

$\alpha_{p}=\frac{1}{2}\left(1-\frac{x}{3 y}\right)$.

The skewed failure plane mechanism in plain concrete under torsion was introduced and verified by Lessig [18] and Hsu [19]. The modulus of rupture $\left(f_{r}\right)$ was used as the critical stress. Later it was observed that the failure appeared in bending of a skew failure plane [20]. The torsional strength based on the skew-bending theory is presented in Eq. 7.

$T=\frac{1}{3} x^{2} y\left(0.85 f_{r}\right)$.

From Bredt's thin-walled tube theory, the torque on a cross section relates to shear flow $(q)$ and its enclosed area $\left(A_{c p}\right)$. For a plane rectangular section, the torsional strength or cracking moment can be obtained by replacing the original area $\left(A_{o}\right)$ of the cross section with an equivalent thin-wall thickness $\left(0.75 A_{c p} / P_{c p}\right)$ and an enclosed area $\left(2 A_{c p} / 3\right)$ as follows [21]:

$q=\frac{\tau}{t}=\frac{T}{2 A_{o}}$

$T=\left(\frac{A_{c p}^{2}}{P_{c p}}\right) \tau=\left(\frac{A^{2} c p}{P_{c p}}\right) f_{c r}$,

where $T$ is applied torque, $t$ is wall thickness, $q$ is shear flow on a cross section, and $f_{c r}$ is critical stress for torsional cracking.

\section{RESULTS}

\subsection{Compressive strength and modulus of rupture}

The results from the first set of experiments (compression strength and modulus of rupture) were assessed from a graph. For the 42 pairs of compressive and flexural data, the compressive strength and the modulus of rupture were evaluated, and are shown in Fig. 6. The ACI empirical formula for modulus of rupture was compared to the experimental results as shown in Fig. 6, and it was found that the modulus of rupture provided by ACI underestimated the experimental results in most cases. As found in several prior studies $[1-4,22,23]$ the ACI empirical formula may be inappropriate for predicting the modulus of rupture. Thus, we looked for a more appropriate empirical formula based on the compressive strength. Regression analysis was used to find the best fits to the modulus of rupture $\left(f_{r}\right)$. The empirical model proposed here for the modulus of rupture is as follows:

$f_{r}=0.70 \sqrt{f_{c}^{\prime}}$, where $f_{c}{ }_{c}$ is compressive strength (in $\mathrm{MPa}$ ), and $f_{r}$ is in the same units.

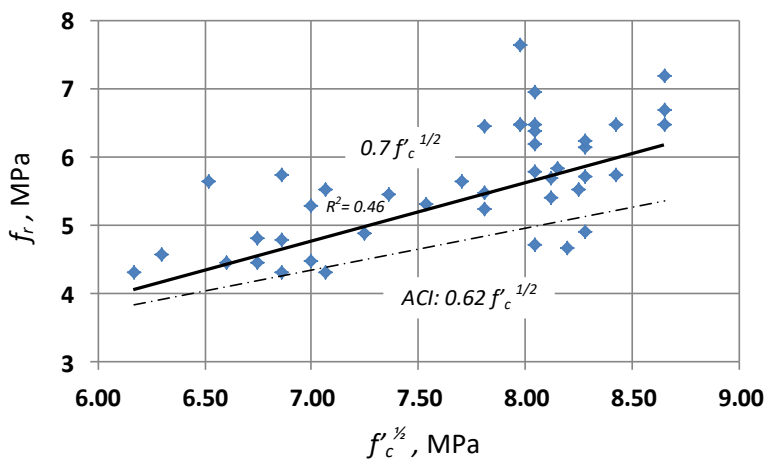

Fig. 6. Relationship of compressive strength - modulus of rupture

The difference in the modulus of rupture estimates from the proposed and from the ACI empirical formula is about $16 \%$. The proposed model will here be used in the torsional strength model of Section 4.2.

\subsection{Compressive and torsional strength}

The prism samples $(25 \times 25 \times 285 \mathrm{~mm})$ under pure torsion exhibited a small inclined crack, initiated at the midpoints of the longer edges of a cross section. Sudden failure of the prism occurred when the maximum principal tensile stress exceeded the tensile strength of the material. The skewed and inclined failure plane is shown in Fig. 5. The correlation of the compressive and torsional strengths across 42 observations is presented in Fig. 7.

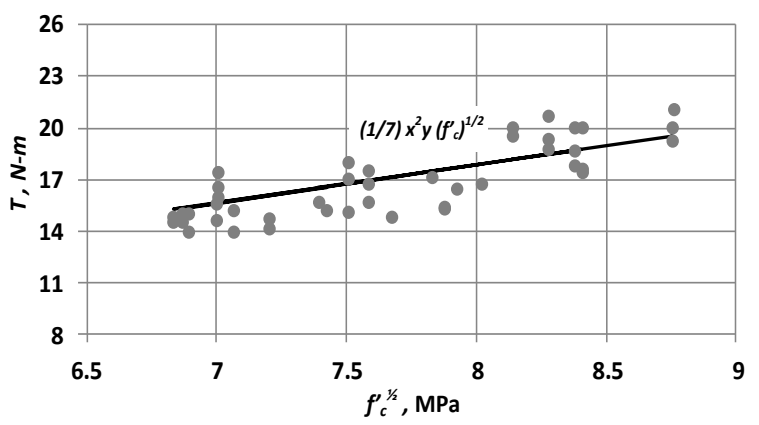

Fig. 7. Relationship of compressive and torsional strengths

A model based on the skew bending theory was developed in this study. For that model, the critical stress was taken as the tensile strength of the material. The coefficients for ordinary concrete in the relations between direct tensile strength, split tensile strength, and modulus of rupture were accepted in this current study, due to limited data on geopolymers. The approximate torsional strength based on the modified skew-bending theory for very early strength geopolymer bar is given in Eq. 11 .

$T=\frac{1}{7} x^{2} y \sqrt{f_{c}^{\prime}}$,

where $f_{c}{ }_{c}$ is the compressive strength (in $\mathrm{MPa}$ ).

The approximate torsional strength is compared to the experimental data in Fig. 8. 


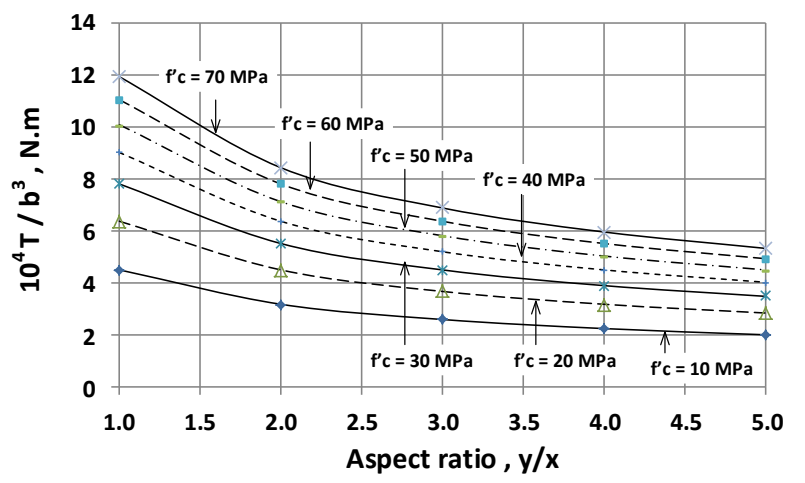

Fig. 8. Relation of torsional strength and aspect ratio $(y / x)$. Note: the cross sectional area yx was held constant.

\section{PARAMETRIC STUDY}

To study effects of the aspect ratio $(y / x)$ on torsional strength, this ratio was varied from 1 to 5 while holding the cross sectional area constant. From Eq. 11, the relation between torsional and compressive strengths suggests that the torsional strength should decrease as the aspect ratio $(y / x)$ increases, while compressive strength is held fixed. The torsional strength indeed was significantly reduced by about $50 \%$ as the aspect ratio (y/x) increased from 1 to 3, with slower decrease thereafter. The strength relations with aspect ratio are presented in Fig. 8 and Fig. 9.

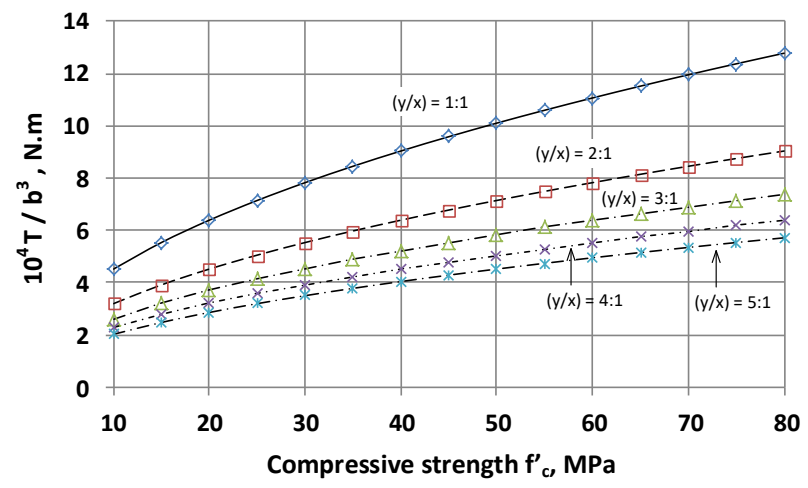

Fig. 9. Relation of torsional strength and compressive strength. Note: the cross sectional area yx was held constant

In general, the members are typically simultaneously subjected to different types of loading. The structural behavior under such combined loads is quite complex and developing an exact model of the structural response in not practical; but an approximate model of structural member responses to combined loads is necessary. The strength and structural responses could be represented by well-known approximations for interacting combined loads. From our experimental data, the interaction of bending and torsion was modeled using the proposed modulus of rupture and torsional strength models. The general interaction [18] is here modified as follows:

$\left(\frac{8.57 M^{*}}{y}\right)+\left(\frac{7 T^{*}}{x}\right)^{2}=1 ;$
$M^{*}=\frac{M}{A \sqrt{f_{c}^{\prime}}}$ and $T^{*}=\frac{T}{A \sqrt{f_{c}^{\prime}}}$,

where $f^{\prime}{ }_{c}$ is compressive strength (in MPa), $A$ is cross sectional area (equaling xy), and $M$ and $T$ are applied bending moment and torque, respectively.

To assess the effects of aspect ratio on strength, the interaction relations in Eq. 12 and Eq. 13 are shown in Fig. 10. When the aspect ratio $(\mathrm{y} / \mathrm{x})$ of a cross section increases the torsional resistance significantly decreases under combined bending and torsion. An almost $50 \%$ reduction in the torsional resistance was observed in comparison to pure torsion, for cases with aspect ratio exceeding 3 .

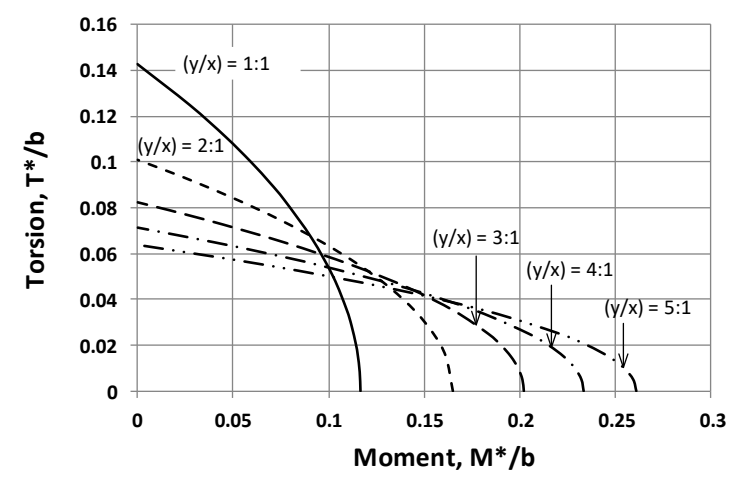

Fig. 10. Failure envelopes for interacting bending and torsion, as the cross-sectional aspect ratio is varied while its area is held fixed

\section{CONCLUSION}

Very high early strength geopolymer based on metakaolin (MK) and Parawood ash (PWA) that has been developed by the authors was experimentally evaluated for resistance to compression, flexural bending and torsion, to establish empirical models of torsion strength in terms of compressive strength. In this study, the modulus of rupture and the torsional strength were approximated by $0.7\left(f^{\prime} c\right)^{1 / 2}$ and $1 / 7\left(x^{2} y\right)\left(f^{\prime} c\right)^{1 / 2}$, respectively. The results from a parametric study showed that torsional strength can be reduced by $50 \%$ when the cross section is shaped to aspect ratio 3 from original square shape, holding its area constant. In addition, interacting combined bending and torsion was studied and modeled. The torsional resistance is significantly decreased by the interaction of loadings, for cases with aspect ratio exceeding 3 .

\section{Acknowledgments}

This study was partially supported by STRuctural Engineering and Applied Mechanics (STREAM) Research Group under Grant ENG-512711022S, Department of Civil Engineering, Faculty of Engineering, Prince of Songkla University, Hat Yai, Songkhla, Thailand. Special thanks go to Dr. Seppo Karrila, Research and Development Office (RDO), Prince of Songkla University for reviewing and correcting the English language. In addition, the authors would also like to thank anonymous reviewers for their valuable and constructive comments. 


\section{REFERENCES}

1. Fernandez-Jimenez, A., Palomo, A. Characterization of Fly Ashes - Potential Reactivity as Alkaline Cement Fuel 82 2003: pp. 2259-2265.

2. Hardjito, D., Wallah, S.E., Sumajouw, D.M.J., Rangan, B.V. On the Development of Fly Ash-Based Geopolymer Concrete ACI Materials Journal 101 (6) 2004: pp. $467-472$.

3. Sofi, M., Van Deventer, J.S., Mendis, P.A., Lukey, G.C. Engineering Properties of Inorganic Polymer Concrete (IPCs) Cement and Concrete Research 37 (2) 2007: pp. $251-257$. https://doi.org/10.1016/j.cemconres.2006.10.008

4. Diaz-Loya, E.I., Allouche, E.N., Vaidya, S. Mechanical Properties of Fly-Ash-Based Geopolymer Concrete ACI Materials Journal 108 (3) 2011: pp. 300-306.

5. Tang, T., Zollinger, D.G. Investigation of Spall Repair for Concrete Pavement, Tech. Rep. 2919-3, Texas Transportation Institute, 1997, Texas A\&M University.

6. Yang, Q. Zhu, B., Zhang, S., Wu, X. Properties and Applications of Magnesia-Phosphate Cement Mortar for Rapid Repair of Concrete Cement and Concrete Research 30 (11) 2000: pp. $1807-1813$.

7. Markey, S.M., Whitney, D.P., Fowler, D.W., Lee, S.I., Mukhopadhyay, A.K., Zollinger, D.G. Investigation of Spall Repair Materials for Concrete Pavement, Tech. Rep. 0-51101, Center for Transportation Research, 2006, University of Texas at Austin.

8. Buch, N., VanDam, T.J., Peterson, K., Sutter, L. Evaluation of High-Early Strength PCC Mixtures Used in Full Depth Repairs Construction and Building Materials 22 (3) 2008: pp. $162-174$.

9. Won, J.P., Kim, J.M., Lee, S.J., Lee, S.W., Park, S.K. Mix Proportion of High-Strength, Roller-Compacted, Latex-Modified Rapid-Set Concrete for Rapid Road Repair Construction and Building Materials 25 (4) 2011: pp. $1796-1800$.

10. Hawa, A., $\quad$ Tonnayopas, D., $\quad$ Prachasaree, W., Taneerananon, $\mathbf{P}$. Development and Performance Evaluation of Very High Early Strength Geopolymer for Rapid Road Repair Advances in Materials Science and Engineering Article ID 764180, 2013: 9 pages.

11. Hawa, A., Tonnayopas, D., Prachasaree, W. Performance Evaluation of Metakolin Based Geopolymer Containing Parawood Ash and Oil Palm Ash Blends Materials Science 20 (3) 2014: pp. 339-344.

12. European Standard. Cement composition, specifications and conformity Criteria for common cements, 2000, EN $197-1$.
13. American Society for Testing and Materials. Standard Test Method for Relative Density (Specific Gravity) and Absorption of Fine Aggregate, ASTM C128, Annual Book of ASTM Standards, 2015, West Conshohocken, PA.

14. Patil, K.K., Allouche, E. Effect of Alkali Silica Reaction (ASR) in Geopolymer Concrete. World Coal Ash (WOCA) Conference. May 9-12, 2011, Denver, CO, USA.

15. Chareerat, T. A Study of Compressive Strength and Durability of Mae Moh Fly Ash Geopolymer. A thesis of Degree of Doctor of Philosophy in Civil Engineering, Khon Kean University, 2008.

16. American Society for Testing and Materials. Standard Test Method for Compressive Strength of Hydraulic Cement Mortars (Using 2-in (or $50 \mathrm{~mm}$ ) Cube Specimens), ASTM C109/109M, Annual Book of ASTM Standards,2008, West Conshohocken, PA.

17. American Society for Testing and Materials. Standard Test Method for Flexural Strength of Concrete (Using Simple Beam With Center-Point Loading), ASTM C293, Annual Book of ASTM Standards, 2002, West Conshohocken, PA.

18. Lessig, N.N. The Determination of The Load Bearing Capacity of Rectangular Reinforced Concrete Sections Subject to Combined Torsion and Bending, Trudy No. 5, Concrete and Reinforced Concrete Institute (Moscow), 1959: pp. 5-28.

19. Hsu, T.T.C. Torsion of Structural Concrete-Plain Concrete Rectangular Sections, Torsion of Structural Concrete, Special Publication No. 18-8, American Concrete Institute, Detroit, 1966: pp. $203-238$.

20. Martin, L.H. Bending and Torsion of Plain Concrete Members Building Sciences 6 1971: pp. 253-265.

21. Hassoun, M.N., Al-Manaseer, A. Structural Concrete Theory and Design, $3^{\text {rd }}$ edition, John Wiley \& Sons. Inc., Hoboken, New Jersey, 2005.

22. Wongpa, J., Kiattikomol, K., Jaturapitakkul, C., Chindaprasirt, P. Compressive Strength, Modulus of Elasticity, and Water Permeability of Inorganic Polymer Concrete Materials and Design 31 2010: pp. $4748-4754$.

23. Prachasaree, W., Limkatanyu, S., Hawa, A., Samakrattakit, A. Development of Equivalent Stress Block Parameters for Fly-Ash-Based Geopolymer Concrete Arabian Journal for Science and Engineering 39 (12) 2014: pp. 8549 - 8558 . https://doi.org/10.1007/s13369-014-1447-2 